\title{
EDITORIAL
}

\section{Celebrating 150 years of the NSIS and Maritime Science: Reflecting on the Society's Role, and Identifying Future Roles and Challenges}

The Nova Scotian Institute of Science (NSIS) celebrates its 150th Anniversary in 2012. It was founded in Halifax in May, 1862, originating from the Halifax Mechanics' Institute (1831-1860) and the Halifax Literacy and Scientific Society (1839-1862). It was originally called the Nova Scotian Institute of Natural Science, as early areas of interest were geology, minerals, botany, zoology, meteorology and physical geography, and the economic potential of natural resources. The Institute received its first grant from the Nova Scotia Legislature in 1867; it was incorporated in the Province by an Act of the Legislature in 1890 and the Revised Statutes of Nova Scotia in 1967.

The NSIS is the oldest, continuous scientific organization and one of the oldest learned societies in Canada. As such, it has been a focal point for the important role and contributions of science in the Maritime Provinces and Atlantic Canada from just before Confederation (1867) to the present day. The Maritimes and Nova Scotia in particular, with many universities and research institutes, have produced a plethora of prominent scientists and key discoveries. These range from Abraham Gesner, inventor of kerosene, to fundamental discoveries in marine ecology and oceanography (with key marine science laboratories in Halifax, Dartmouth and St. Andrews, NB), to the most recent recognition of Willard S. Boyle who shared the 2009 Nobel Prize in Physics for his work developing the sensor widely used in digital cameras. The Institute played a key role in the establishment of the Provincial Natural History Museum in Halifax. As well, Nova Scotia is the home to the Pugwash Conferences, a meeting place of the world's most prominent scientists.

Being 150 years old is a major achievement. The organization has been a stimulus and focal point for scientific progress, reporting and communication in the Maritime Provinces. The Proceedings have been published from the beginning, with many distinguished contributors writing on a wide spectrum of topics. Each year the NSIS organizes a lecture series that includes topics of current interest. Over the years, 
hundreds of monthly lectures have been given, communicating scientific research and achievements to members and to the broader community. The lectures are often published in the Proceedings.

In this issue we include a paper on bats which have been in the news lately for two reasons. Firstly, large numbers of migrating bats are killed each year by wind turbines, but recent research has shown that deaths can be reduced by $50-75 \%$ if the turbines are shut down at low wind speeds when they generate very little electricity. The second concern about bats is occurrence of a new fungal disease called 'white-nose syndrome' which seems to have spread from Europe to the USA, where it was first recorded in 2006. Since then, the disease has been reported in many states and has spread to at least four Canadian provinces. Mortality rates for the disease often exceed $90 \%$ for bat species that hibernate in caves during winter. In addition to bat-to-bat infection, the disease is being spread from cave to cave inadvertently by cavers and geocaching enthusiasts. The concern about bat populations is so serious that COSEWIC (Committee on the Status of Endangered Wildlife in Canada) has called for special reports on three bat species. The paper in this issue is a significant contribution to our understanding of bat biology in Nova Scotia.

The year 2012 has many local and global anniversaries with a science theme, and this gives us pause for thought. Locally, the Bedford Institute of Oceanography in Dartmouth, NS, is 50 years old and is planning a book detailing its various achievements in ocean science during the period 1962-2012. Rachel Carson's Silent Spring, published in 1962 to alert the world to the perils of toxic chemicals, galvanized a generation of environmentalists and concerned scientists; Carson emphasized the wide spread use and impacts of pesticides, and referred to aquatic studies on salmon and DDT conducted in New Brunswick in the 1950s by Maritime scientists. This influential book is still a best seller and will undoubtedly be celebrated widely in 2012. As well, the active American Scientific Research Society, Sigma Xi, is celebrating its 125th anniversary, with an emphasis on how science serves society and the role of team science in the 21 st century. As a local aside, the ocean liner Titanic, a marvel of nautical engineering but a 20th Century example of technological hubris, hit an iceberg and sank in 1912, a fact hard to forget if you live in Halifax and visit the Maritime Museum! The liner resting at the bottom of the NW Atlantic has been studied by local scientists in recent years. These are but a few of the 
current science-related anniversaries; the reader probably knows of many more. Clearly, 2012 is a year to celebrate science!

Today, NSIS serves Nova Scotia and the Maritime region of Canada by:

- Providing a forum for scientists and those interested in science to learn about and discuss scientific matters, through a monthly public lecture and discussion series, its journal (The Proceedings of the NSIS), and its website;

- Drawing attention to issues of societal concern that intersect the natural and social sciences, such as education, environmental and natural resource policies, and ethics;

- Promoting research and education in science by running a Mentorship Program, conducting an annual Scientific Writing Competition for university students, and supporting Regional Science Fairs;

- Presenting current and historical material of Canadian scientific importance to the public on its website, www.chebucto.ns.ca/ science/nsis; and

- Housing the NSIS virtual Hall of Fame for men and women who have contributed significantly to the scientific activity of Nova Scotia, Canada, and the world beyond our borders (see website).

Noting this, what should the NSIS anniversary mean to members of the Society and to the interested public? Celebrating NSIS in 2012 and the achievements of science in Nova Scotia and the Maritimes brings attention to:

- the pivotal role of the natural and social sciences and researchers in Canada's history and development as a nation;

- the cornerstone role of science in Canada's future prosperity in an ecologically and economically sustainable world; and

- the contributions of regional scientific societies in Canada to communicating science to the broader interested public and to encouraging careers in science in Canada.

In addition, 2012 provides an opportunity to celebrate Maritime science and the scientific enterprise as a whole, in all of its dimensions and with all of its societal benefits. We can contemplate future challenges where all branches of science play a pivotal role in our society. It is 
an opportunity for NSIS to enlarge and broaden its membership, to distribute its Proceedings more widely in digital and paper formats, and to reinvigorate its website. 2012 is a time to defend the importance of science in all of our institutions, especially in the Public Service, during a time of economic downturns and debt-related cutbacks. It is a time to strengthen linkages with other scientific organizations, such as the Royal Society of Canada and specialized professional groups, and to collaborate with the scientific activities of citizen-driven, nongovernmental organizations. It is a time to sponsor forward-looking seminars and workshops so that science and science education are strong players in our future Maritime economy and culture. Clearly the NSIS and its members have a key role to play now and over the next 150 years!

Peter G. Wells, Editor

David H. S. Richardson, Associate Editor 